\title{
IgG4-related disease: what a hematologist needs to know
}

Haematologica 2019

Volume 104(3):444-455

\section{Correspondence:}

LUKE Y.C. CHEN

Ichen2@bccancer.bc.ca

Received: October 23, 2018.

Accepted: January 7, 2019.

Pre-published: January 31, 2019.

doi:10.3324/haematol.2018.205526

Check the online version for the most updated information on this article, online supplements, and information on authorship \& disclosures: www. haematologica.org/content/104/3/444

\section{(C)2019 Ferrata Storti Foundation}

Material published in Haematologica is covered by copyright. All rights are reserved to the Ferrata Storti Foundation. Use of published material is allowed under the following terms and conditions:

https://creativecommons.org/licenses/by-nc/4.0/legalcode. Copies of published material are allowed for personal or internal use. Sharing published material for non-commercial purposes is subject to the following conditions:

https://creativecommons.org//icenses/by-nc/4.0/legalcode, sect. 3. Reproducing and sharing published material for commercial purposes is not allowed without permission in writing from the publisher.

\section{Luke Y.C. Chen, ${ }^{1}$ Andre Mattman, ${ }^{2}$ Michael A. Seidman ${ }^{2,3}$ and Mollie N. Carruthers ${ }^{3}$}

${ }^{1}$ Division of Hematology, Department of Medicine, University of British Columbia; 2Department of Pathology and Laboratory Medicine, St. Paul's Hospital and ${ }^{3}$ Division of Rheumatology, Department of Medicine, University of British Columbia, Vancouver, BC, Canada

\section{ABSTRACT}

TgG4-related disease is a fibro-inflammatory condition that can affect nearly any organ system. Common presentations include major salivary and lacrimal gland enlargement, orbital disease, autoimmune pancreatitis, retroperitoneal fibrosis and tubulointerstitial nephritis. This review focuses on the hematologic manifestations of IgG4-related disease, including lymphadenopathy, eosinophilia, and polyclonal hypergammaglobulinemia. The disease can easily be missed by unsuspecting hematologists, as patients may present with clinical problems that mimic disorders such as multicentric Castleman disease, lymphoma, plasma cell neoplasms and hypereosinophilic syndromes. When IgG4-related disease is suspected, serum protein electrophoresis and IgG subclasses are helpful as initial tests but a firm histological diagnosis is essential both to confirm the diagnosis and to rule out mimickers. The central histopathological features are a dense, polyclonal, lymphoplasmacytic infiltrate enriched with IgG4-positive plasma cells (with an IgG4/IgG ratio $>40 \%$ ), storiform fibrosis, and obliterative phlebitis. Importantly for hematologists, the latter two features are seen in all tissues except bone marrow and lymph nodes, making these two sites suboptimal for histological confirmation. Many patients follow an indolent course and respond well to treatment, but a significant proportion may have highly morbid or fatal complications such as peri-aortitis, severe retroperitoneal fibrosis or pachymeningitis. Corticosteroids are effective but cause new or worsening diabetes in about $40 \%$ of patients. Initial response rates to rituximab are high but durable remissions are rare. More intensive lymphoma chemotherapy regimens may be required in rare cases of severe, refractory disease, and targeted therapy against plasmablasts, IgE and other disease biomarkers warrant further exploration.

\section{Example case}

An 80-year old Korean man was referred for evaluation of chronic lymphadenopathy, eosinophilia and polyclonal hypergammaglobulinemia. He had had abdominal pain since the 1970s and was initially thought to have Crohn disease, subsequently complicated by idiopathic common bile duct narrowing. In the 1990s, he was found to have a kidney mass on computed tomography which was suspected to be lymphoma, but after the mass was resected, the histology was in keeping with multifocal fibrosclerosis. At the time of referral, his physical examination revealed a low, firm, slightly enlarged, left submandibular gland, no lacrimal gland swelling, and multiple $2 \mathrm{~cm}$ or smaller soft inguinal lymph nodes bilaterally. His white blood cell count was $8.3 \times 10^{\circ} / \mathrm{L}$, eosinophil count $2.0 \times 10^{\circ} / \mathrm{L}$ (normal values $<0.7 \times 10^{\circ} / \mathrm{L}$ ), creatinine concentration $140 \mu \mathrm{mol} / \mathrm{L}$, total protein $87 \mathrm{~g} / \mathrm{L}$ (normal values $<82$ $\mathrm{g} / \mathrm{L})$, with a polyclonal increase in gamma globulins on serum protein electrophoresis of 20.5 $\mathrm{g} / \mathrm{L}$ (normal values $<14 \mathrm{~g} / \mathrm{L}$ ), and total $\mathrm{Ig} G$ of $28.9 \mathrm{~g} / \mathrm{L}$ (normal values $<18.5 \mathrm{~g} / \mathrm{dL}$ ). 


\section{Introduction}

Immunoglobulin G4-related disease (IgG4-RD) is a chronic immune-mediated disease that may present with tumefactive lesions, fibrosis, and a polyclonal IgG4-positive $\left(\operatorname{IgG} 4^{+}\right)$plasma cell-enriched infiltrate in nearly any anatomic site. In many centers, systemic therapy is guided by rheumatologists, yet nearly every medical, surgical and pathology specialty must be aware of this entity and its protean manifestations. Involvement of blood-forming and lymphoid organs, manifesting as lymphadenopathy, eosinophilia, and polyclonal hypergammaglobulinemia, is common and IgG4-RD often mimics other hematologic conditions such as multicentric Castleman disease, lymphoma, plasma cell neoplasms, and hypereosinophilic syndromes (HES). This review provides an overview of IgG4-RD with a focus on aspects most relevant to clinical hematology practice.

In the early 2000s, while searching for non-invasive biomarkers to distinguish sclerosing (autoimmune) pancreatitis from pancreatic cancer, Japanese investigators noticed a fast-moving band in the beta-gamma region of the serum protein electrophoresis of patients with sclerosing pancreatitis. This band represented markedly elevated serum IgG4. ${ }^{1}$ Subsequently, abundant polyclonal IgG4+ $4^{+}$plasma cells were found within a lymphoplasmacytic infiltrate in tissue samples from patients with autoimmune pancreatitis and in surrounding tissues including the liver and gallbladder. ${ }^{2}$ Once this entity was recognized as a distinct disease with characteristic histological features, many historically "idiopathic" and eponymous disorders such as multifocal fibrosclerosis (mediastinal and retroperitoneal fibrosis), Kuttner tumor (chronic sclerosing sialadenitis) and Reidel thyroiditis (woody infiltration of the thyroid) were found to be part of the IgG4-RD spectrum. ${ }^{3}$ Numerous names were proposed in the early days of its discovery, including "IgG4-related sclerosing disease", "IgG4-related systemic disease", "IgG4-related multiorgan lymphoproliferative syndrome" and "systemic IgG4-related plasmacytic syndrome". An international group of investigators, primarily from Japan, the USA and Europe met in Boston in 2011 and agreed upon uniform nomenclature and diagnostic criteria. ${ }^{3}$ The accepted name "IgG4-related disease" reflects the universality of the $\operatorname{IgG} 4^{+}$plasma cell infiltration in involved organs as well as the frequency of elevation in serum IgG4 rather than a pathogenic role for IgG4 per se. ${ }^{4}$ The wide variety of disease manifestations stems not only from multi-organ involvement, but also from the fact that different organs may be involved in a metachronous fashion. Common presentations are major salivary (parotid and submandibular) and lacrimal gland enlargement (Mickulicz disease), lymphadenopathy, orbital pseudotumor, pancreatitis, sclerosing cholangitis, retroperitoneal fibrosis and tubulointerstitial nephritis. ${ }^{5}$

\section{Epidemiology and pathophysiology}

Underrecognition has hindered accurate estimates of the epidemiological burden of this disease, but a starting point is the prevalence of autoimmune pancreatitis in Japan, which increased from 2.2/100 000 in 2007 to $4.6 / 100000$ in 2011 . The increase is almost certainly due to increased recognition, and given that pancreatic involvement is present in about $20-25 \%$ of IgG4-RD cases, the true prevalence of the disease is likely much higher. There is a 2:1 male preponderance and the median age of affected patients at diagnosis is in the sixth to seventh decade of life. Aside from one case report of identical twins with IgG4-RD, ${ }^{6}$ evidence of genetic susceptibility is sparse. Pediatric cases are rare, but a recent review identified 25 cases in children, of whom 11 had orbital disease and three had autoimmune pancreatitis.'

At first glance, the presence of IgG4 in serum and IgG4 plasma cells in tissues, increased $\mathrm{IgG}^{+}$plasmablasts in serum, and responsiveness to rituximab suggest that B-cell activation drives the disease. ${ }^{8}$ However, the IgG4 antibody itself is not thought to be pathogenic since it does not bind complement, does not traditionally form immune complexes, and patients with other conditions with markedly elevated serum IgG4, such as IgG4 myeloma, do not develop features of IgG4-RD., 910 Recent studies have demonstrated that an unconventional population of $\mathrm{CD}^{+} \mathrm{SLAMF7}^{+}$cytotoxic T lymphocytes is central to the pathogenesis of the disease. ${ }^{11}$ Histopathologically, polyclonal $\mathrm{B}$ cells are found in clusters near these $\mathrm{CD} 4^{+} \mathrm{T}$ cells, the latter of which are among the most abundant cells within affected tissues. Oligoclonal expansion of these $\mathrm{CD}^{+}$cytotoxic $\mathrm{T}$ lymphocytes in peripheral blood may explain the high rates of T-cell clonality positivity determined by polymerase chain reaction analysis. ${ }^{12}$ These $\mathrm{CD}^{+} \mathrm{T}$ cells produce profibrotic cytokines such as interleukin-1, transforming growth factor-beta and interferongamma, as well as cytolytic molecules such as granzyme $A$ and $B$ and perforin. ${ }^{13}$ These cytotoxic $T$ lymphocytes are likely sustained by continuous antigen presentation by $\mathrm{B}$ cells and plasmablasts. The responsible autoantigen(s) have not been definitively identified, but annexin A11 and galactin-3 have both recently been implicated in IgG4RD. ${ }^{14,15}$ The autoantibody response to galactin- 3 is primarily of the IgG4 and IgE isotypes, which correlates with the typical immunoglobulin responses seen in IgG4-RD.

\section{Clinical presentation}

IgG4-RD can affect nearly any organ except synovial tissue. This "fibro-inflammatory" disease presents with tumefactive (puffy) inflammatory infiltrates and fibrosis with a predilection for glandular tissue. Figure 1 illustrates the manifestations of IgG4-RD by organ system. The most common organ manifestations from two large cohorts, one Japanese and one American, are shown in Table $1 .{ }^{16,17}$ In patients presenting with the better-known features of IgG4-RD, such as autoimmune pancreatitis, orbital disease and major salivary gland involvement, the disease tends to be recognized and histologically confirmed earlier, but patients referred to hematologists may present with less obvious features of IgG4-RD, and a high index of suspicion is needed to arrive at an accurate diagnosis. Common reasons for referral to a hematologist include lymphadenopathy, eosinophilia, and polyclonal hypergammaglobulinemia.

\section{Lymphadenopathy}

IgG4-related lymphadenopathy is one of the three most common manifestations of IgG4-RD, affecting 30-60\% of patients with IgG4-RD in most large cohorts (Table 1).5,16,17 IgG4-lymphadenompathy may be generalized or local- 


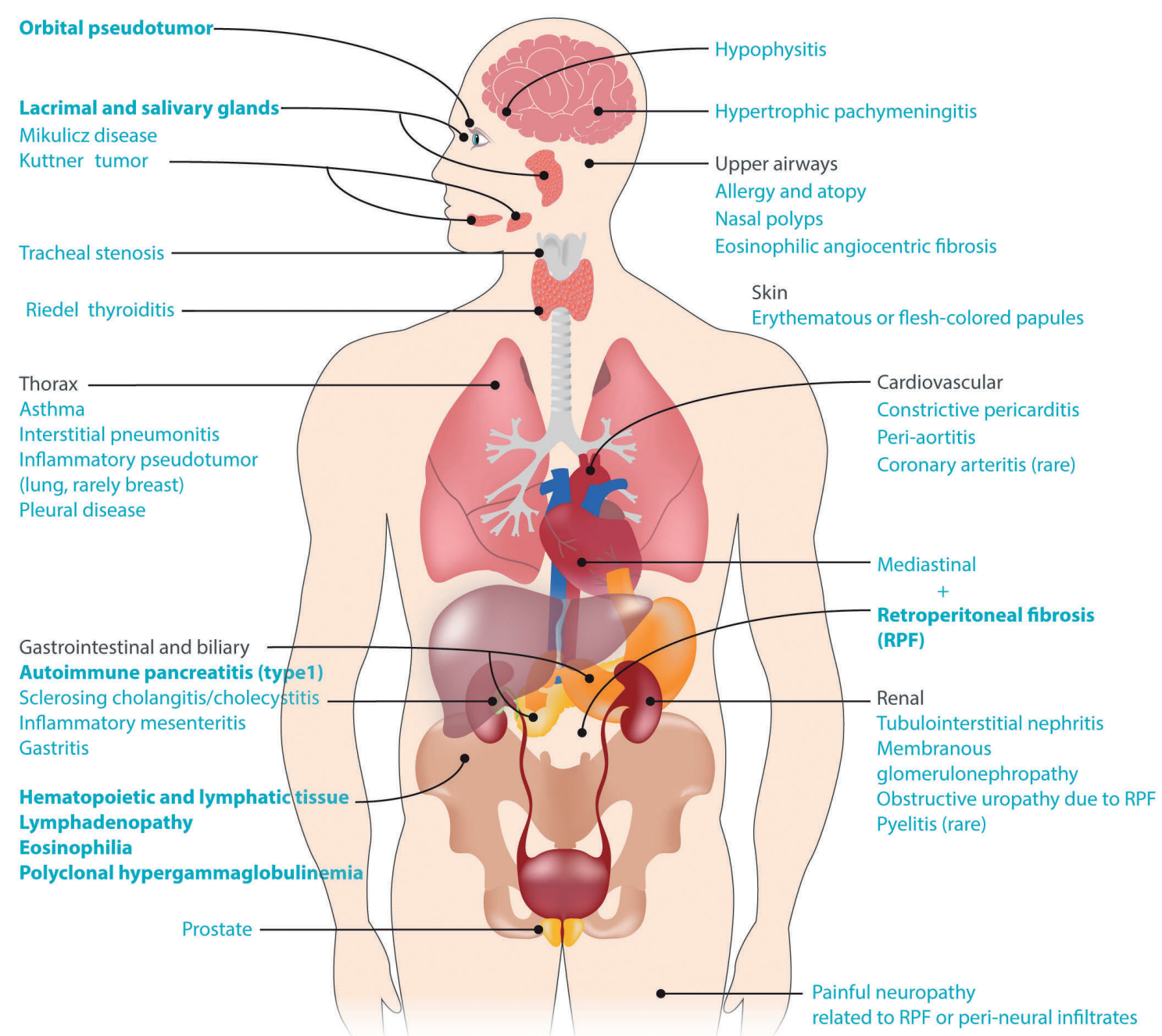

Figure 1. Manifestations of IgG4-related disease by organ system. The most common primary disease features are indicated in bold.

ized (the latter typically contiguous with involved organs such as pancreas and lungs). Parallel enlargement of salivary, lacrimal and parotid glands is common. Five morphological subtypes, all of which display increased IgG4 ${ }^{+}$ plasma cells, have been described (see Figure 2 for examples): ${ }^{18-20}$

(i) Multi-centric Castleman disease-like: preserved nodal architecture with patent sinusoids and hyperplastic follicles; abundant mature plasma cells in interfollicular areas with some eosinophils, similar to lymphadenopathy in multicentric Castleman disease or autoimmune disease.

(ii) Reactive follicular hyperplasia: increased IgG4+ plasma cells in germinal centers and often in the interfollicular zones with some eosinophils present.

(iii) Interfollicular expansion pattern: expanded interfollicular zones with small lymphocytes, plasmablasts and mature plasma cells and eosinophils which may resemble lymphoma (e.g. angioimmunoblastic lymphoma). Examples are given in Figure 2A-C.

(iv) Progressive transformation of germinal center-like:
Table 1. Clinical characteristics of patients from two large published cohorts.

\begin{tabular}{lcc} 
& Japan $(\mathbf{n = 3 3 4})^{17}$ & Boston $(\mathbf{1 2 5})^{16}$ \\
Mean age at diagnosis & 63.8 years & 55.2 years \\
Male sex & $61.4 \%$ & $60.8 \%$ \\
\hline Ethnicity & $100 \%$ Japanese & $76 \%$ White \\
Elevated serum IgG4 & $>95 \%$ & $51 \%$ \\
\hline Mean number of organs & $3.2(1-11)$ & $2.3(1-7)$ \\
involved (range) & & \\
Affected organs & & \\
Salivary glands & $72.3 \%$ & $28 \%$ (submandibular) \\
& & $+16.8 \%$ (parotid) \\
Lacrimal glands/orbit & $57.1 \%$ & $22.4 \%$ \\
Lymph nodes & $56.5 \%$ & $27.2 \%$ \\
Pancreas & 25.5 & $19.2 \%$ \\
Retroperitoneal/aorta & 24.9 & $18.4 \%$ (retroperitoneal) \\
& & $+11.2 \%$ (aorta) \\
Kidney & $23.7 \%$ & $12 \%$ \\
Lung & $23.4 \%$ & $17.6 \%$ \\
& & \\
\end{tabular}


scattered larger or transformed follicles containing plasma cells. An example is given in Figure 2D,E.

(v) Inflammatory pseudotumor-like: lymph node partially effaced by a fibro-inflammatory infiltrate and storiform fibrosis; this subtype is considered most specific for IgG4$\mathrm{RD}$ in lymph nodes. An example is given in Figure $2 \mathrm{~F}$.

IgG4-related lymphadenopathy has aptly been called both "an underdiagnosed and overdiagnosed entity": ${ }^{19}$ underdiagnosed because if it is not included in the differential diagnosis, IgG4 and IgG stains may not be done and the disease may be missed, and overdiagnosed because increased IgG4 $4^{+}$plasma cells may be seen in conditions ranging from Rosai-Dorfman-Destombes disease to inflammatory vasculitis. ${ }^{21,22}$ Although not the optimal tissue for making the histological diagnosis of IgG4-RD, in a patient with typical clinical features such as autoimmune pancreatitis or retroperitoneal fibrosis, a lymph node biopsy may be sufficient for diagnosis if biopsy of other affected organs is not feasible. Given the low specificity of increased IgG4+ $4^{+}$lasma cells in lymph node and the variable histological patterns, the greatest utility of lymph node biopsy is perhaps excluding other diagnoses, such as lymphoma and HHV8-associated Castleman disease. The role of lymph node biopsy is further discussed in the section on "Diagnosis and staging".

\section{Eosinophilia}

Approximately $40 \%$ of patients with IgG4-RD have peripheral blood eosinophilia, often accompanied by asthma and atopy. ${ }^{23}$ Thus, IgG4-RD is an important and underappreciated cause of reactive or secondary eosinophilia. ${ }^{12}$ HES and IgG4-RD commonly involve the skin, lungs, gas- trointestinal tract, and lymph nodes. ${ }^{12}$ Idiopathic HES and hypereosinophilia of unknown significance are diagnoses of exclusion, and account for a substantial proportion (30$50 \%$ ) of diagnoses of patients evaluated for eosinophilia. ${ }^{24}$ ${ }^{26}$ Evaluating these patients for IgG4-RD is an important and underappreciated aspect of their care. In fact, we previously published a case report with a diagnostic label of idiopathic HES, reviewed by several world experts in eosinophilia who concurred with the diagnosis, which was subsequently found to be IgG4-RD. ${ }^{27,28}$ Findings of a myeloid clonal disorder such as increased blast cells, abnormal karyotype, mutations in PDGFR-alpha/beta, FGFR-1 and PCM1-JAK2 are not seen in IgG4-RD. However, differentiating lymphocytic-variant HES from IgG4-RD can be more challenging. The aberrant T-cell phenotypes found in lymphocytic-variant HES, including increased $\mathrm{CD}^{+} \mathrm{CD}^{-}, \mathrm{CD}^{+} / \mathrm{CD}^{-} / \mathrm{CD}^{-}$and $\mathrm{CD}^{+} / \mathrm{CD}^{-} \mathrm{T}$ cells, with or without $\mathrm{T}$-cell clonality as determined by polymerase chain reaction analysis, have all been reported in IgG4-RD. ${ }^{12,29}$ Increased IgG4 deposits have been found in tissue samples from adult and pediatric patients with eosinophilic esophagitis. ${ }^{30-33}$ In contrast to HES and chronic eosinophilic leukemia, the eosinophilia secondary to IgG4-RD is typically mild to moderate, rarely exceeding $5 \times 10^{9} / \mathrm{L}$ and typically quite evanescent, being ablated by steroids or rituximab therapy.

\section{Polyclonal hypergammaglobulinemia}

As for eosinophilia, IgG4-RD represents an important new diagnostic consideration in patients with hypergammaglobulinemia. An elevated serum IgG4 level, often accompanied by an increase in IgG1, causes polyclonal hypergammaglobulinemia. Rarely, this elevation can be

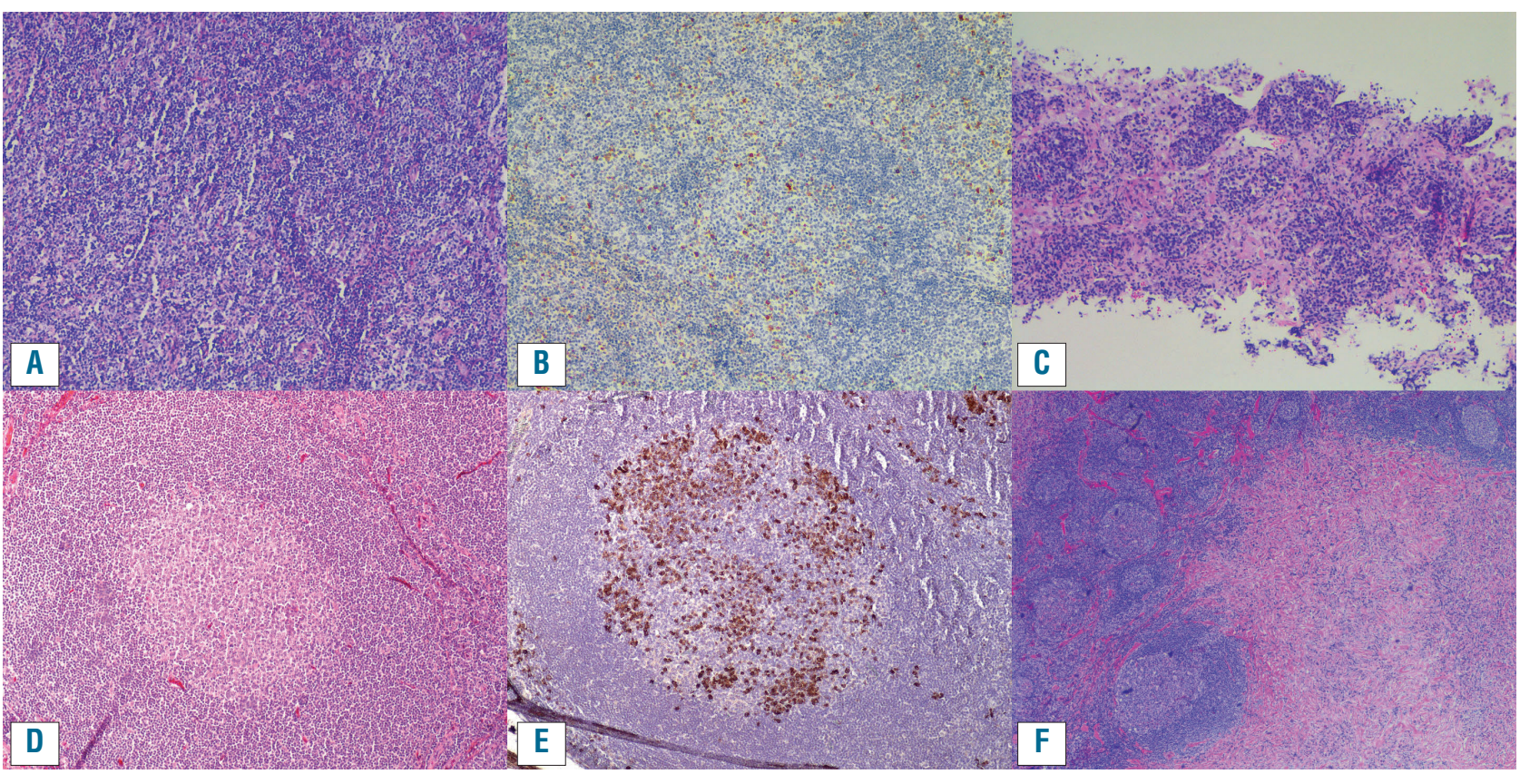

Figure 2. Lymph nodes in IgG4-related disease. (A,B) An example of the interfollicular pattern of lgG4-related lymphadenopathy, with mature plasma cells, many expressing IgG4, distributed between benign follicles. (A) Hematoxylin and eosin stain. (B) IgG4 immunohistochemistry. (C) A needle core lymph node biopsy from a different case with the interfollicular pattern (hematoxylin and eosin stain). (D,E) A case of IgG4-lymphadenoapthy with a progressive transformation of the follicular center pattern, with the plasma cells within the follicle proper. (D) Hematoxylin and eosin stain. (E) IgG4 immunohistochemistry. (F) An example of a mass-like lesion (inflammatory pseudotumor) with dense fibrosis and associated follicular hyperplasia in a case of IgG4-lymphadenoapthy (hematoxylin and eosin). 
sufficient to result in polyclonal hyperviscosity syndrome..$^{27,28,34}$ It is not known what causes the exuberant production of IgG4 immunoglobulins, currently considered an epiphenomenon rather than a contributor to the pathogenesis of the disease. ${ }^{8}$ Not surprisingly, the serum free light chains tend to be abnormally elevated..$^{35} \operatorname{IgE}$ is often markedly increased, particularly in patients with eosinophilia and atopy, whereas IgA and IgM levels are normal or modestly elevated. Serum IgG4 typically runs in the fast gamma or beta-gamma region on the serum protein electrophoresis, and thus the typical electrophoretic profile of a patient with IgG4-RD demonstrates polyclonal hypergammaglobulinemia with beta-gamma bridging. This sometimes prominent pattern is dependent on IgG4 concentration and is highlighted in Figure 3. The hypergammaglobulinemia can be mistaken for a polyclonal increase in $\operatorname{IgA}$, monoclonal gammopathy of undetermined significance or "biclonal" IgG kappa and lambda gammopathy, as laboratory physicians may not be familiar with the dense bands of IgG-lambda and kappa which in fact represent polyclonal IgG4. ${ }^{36,37}$ Some patients have even been treated for myeloma before subsequently being found to have IgG4-RD as the cause of their protein abnormalities, plasmacytosis and renal disease..$^{9,38}$ Laboratory physicians must, therefore, consider the differential diagnosis of beta-gamma bridging and order or suggest additional investigations to clarify clonality and heavy chain composition where necessary. ${ }^{39,40}$

Prior to the recognition of IgG4-RD, a large case series of 130 patients with polyclonal hypergammaglobulinemia $>30 \mathrm{~g} / \mathrm{L}$ on serum protein electrophoresis showed that the most common single diagnoses were liver disease (79/130, $66 \%$ ), connective tissue disease $(28 / 130,22 \%)$, chronic infection $(8 / 130,6 \%)$ and hematologic disorders $(7 / 130$, $5 \%){ }^{41}$ In a recent, single-center study of 70 patients with polyclonal increases in $\operatorname{IgG} \geq 20 \mathrm{~g} / \mathrm{L}$ it was found that 14 $(20 \%)$ had IgG4-RD as the cause of their hypergammaglobulinemia, indicating that a substantial proportion of patients with hypergammaglobulinemia have IgG4-RD as the underlying cause. ${ }^{42}$ The discovery of IgG4-RD has also led to increased recognition of other IgG subclass elevations with specific diseases, such as hepatitis $\mathrm{C}$ and mono- clonal gammopathy of undetermined significance with IgG1, hypothyroidism and irritable bowel syndrome with IgG2, rheumatoid arthritis with increased IgG3 and IgG1, and celiac disease with IgG4. ${ }^{43}$

IgG4 myeloma has been described but is rare; one large case series found that $6 / 158$ bone marrow biopsies in myeloma patients expressed IgG4, in keeping with the relatively small fraction of overall circulating gamma globulins normally made up by the IgG4 subtype..$^{10}$ One case report of IgG4 subtype POEMS has been reported. ${ }^{44}$ The bone marrow morphology may mimic myeloma with florid plasmacytosis, ${ }^{9,45}$ although in our experience, bone marrow examination is very insensitive for the diagnosis of IgG4-RD, with many cases showing no increase in plasma cells or lymphocytes despite florid hypergammaglobulinemia.

\section{Important mimickers of IgG4-related disease}

The diagnostic challenge of IgG4-RD for hematologists is heightened by overlap of clinical and laboratory features with those of a number of other hematologic diseases including lymphoma, plasma cell neoplasms, and histiocyte disorders (Table 2). In addition to the diseases discussed in this section and presented in Table 2 , there are numerous non-hematologic mimickers reviewed in detail elsewhere. ${ }^{46}$ Careful review of histological specimens and correlation with clinical, laboratory and radiological findings are crucial for solidifying the correct diagnosis. Multicentric Castleman disease and IgG4-RD show considerable overlap given the high frequency of lymphadenopathy, IgG4+ plasma cell-enriched tissue infiltrates and elevated serum IgG4 levels seen in both diseases. ${ }^{18}$ However, IgG4-RD typically affects older patients, rarely exhibits the "hyper-interleukin-6" systemic inflammatory features of multicentric Castleman disease such as fever and elevated C-reactive protein, and the histological features are distinct. The histiocytic disorders RosaiDorfman-Destombes disease and Erdheim-Chester disease both cause inflammatory mass lesions that can mimic IgG4-RD. Histopathological evaluation of RosaiDorfman-Destombes disease can show enrichment of IgG4 ${ }^{+}$plasma cells, ${ }^{22,47}$ but typically in the context of

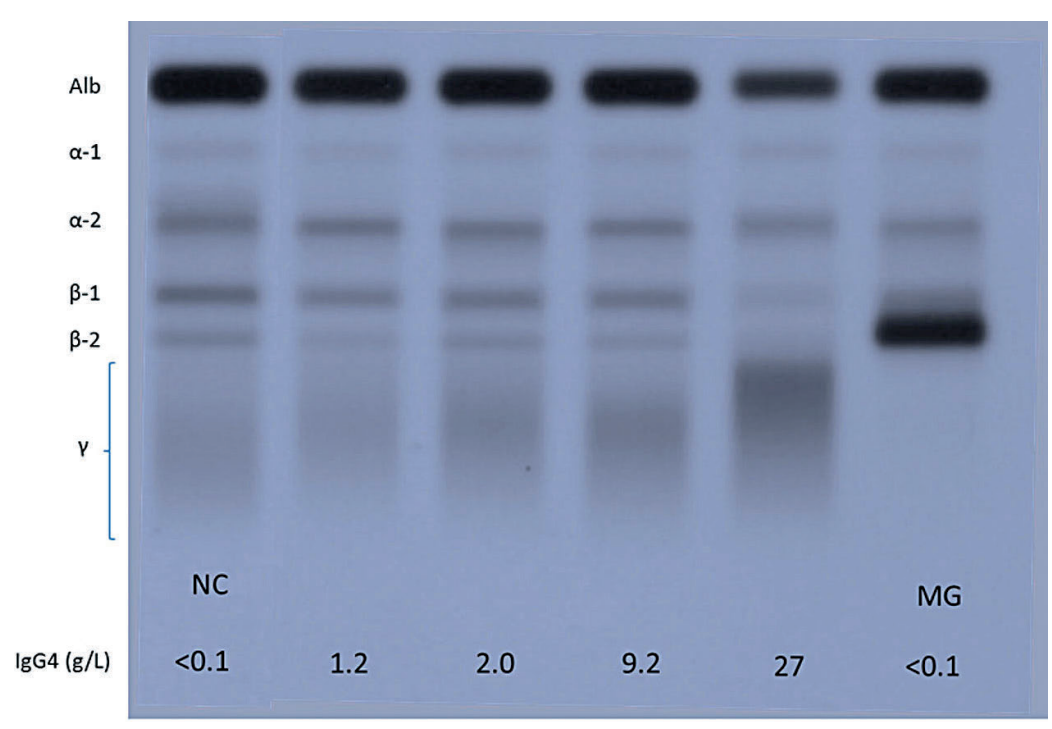

Figure 3. Serum protein electrophoresis showing electrophoretic patterns for four patients with mild to gross elevations in IgG4 concentration in between two for patients with low IgG4 concentration. The physicochemical properties of the IgG4 heavy chain result in a relative anodal position (shift toward albumin) of the gamma globulins when the IgG4 becomes the predominant gamma globulin. Apart from IgG4, IgA immunoglobulins are frequently observed in the boundary between the beta and gamma regions. Monoclonal bands may also migrate in this region as shown in the gel (the monoclonal gammopathy in this case is an IgG1 monoclonal band that has physicochemical properties that are atypical for IgG1 immunoglobulins, which are normally found in a more cathodal position). NC: normal control, MG: monoclonal gammopathy. 
$\mathrm{CD}^{+} 8^{+} \mathrm{S} 100^{+}$histiocytes, often associated with emperipolesis. The most recent classification of the histiocyte disorders recommends evaluating suspected cases of Rosai-Dorfman-Destombes disease for increased IgG4+ plasma cells, ${ }^{48}$ but in the absence of other evidence for a common pathophysiological link, Rosai-DorfmanDestombes disease is not considered part of the spectrum of IgG4-RD or vice versa. ${ }^{49}$ One third of patients with

Table 2. Diseases that mimic hematologic manifestations of IgG4-RD (lymphadenopathy, eosinophilia and polyclonal hypergammaglobulinemia).

\begin{tabular}{|c|c|c|}
\hline Mimicker of Ige4-related disease & Areas of overlap & $\begin{array}{l}\text { Distinguishing features of the mimicker not typically } \\
\text { seen in IgC4-related disease }\end{array}$ \\
\hline Multicentric Castleman disease (MCD) & $\begin{array}{l}\text { - Lymphadenopathy (particularly the MCD-like } \\
\text { variant of IgG4-LAD) } \\
\text { - High serum IgG4 } \\
\text { - IgG4+ plasma cells in tissue* }\end{array}$ & $\begin{array}{l}\text { - MCD is a "hyper-IL-6" syndrome associated with } \\
\text { B symptoms and highly elevated CRP and IL-6 not seen in } \\
\text { IgG4-RD }\end{array}$ \\
\hline
\end{tabular}

Cutaneous and systemic plasmacytosis (CSP)

- Polyclonal hypergammaglobulinemia

- Lymphadenopathy

- Polyclonal hypergammaglobulinemia

- Polyclonal plasmacytosis, including IgG4+

plasma cells in bone marrow and skin*

Rosai-Dorfman-Destombes disease (RDD, a.k.a "Sinus Histiocytosis with Massive Lymphadenopathy; "R" group histiocytosis)

- Lymphadenopathy

- Extranodal RDD can involve the nasal cavity, and retro-orbital tissue

- Meningeal involvement of RDD may mimic IgG4-pachymeningitis

- Salivary gland involvement

- CNS involvement including pachymeningitis

- Increased IgG4+ plasma cells in tissue*

$\begin{array}{ll}\text { Erdheim Chester disease } & \bullet \text { Retroperitoneal fibrosis } \\ \text { (ECD; "L" group histiocytosis) } & \bullet \text { Central nervous system/hypophysitis } \\ & \bullet \text { Pulmonary involvement }\end{array}$

-

\begin{tabular}{ll}
\hline Malignant lymphoma & $\bullet$ Lymphadenopathy \\
& $\bullet$ Extranodal mass lesions \\
& $\bullet$ Blood and tissue eosinophilia
\end{tabular}

Sarcoidosis
Hypereosinophilic syndrome (HES)/chronic
eosinophilic leukemia (CEL)

[particularly lymphocyte-variant HES]

- Lymphadenopathy

- Pulmonary nodules

- Pachymeningitis and/or hypophysitis

- Polyclonal hypergammaglobulinemia

- Multi-organ involvement

- T-cell clonality by PCR

- Atopy/asthma/elevated IgE

- Lymphadenopathy

- Eosinophilia

- Elevated serum IgG4

- Aberrant T cell phenotype in peripheral blood (CD4 $\left./ 3, \mathrm{CD}^{+} / 7^{-}, \mathrm{CD}^{+} / 4^{-/ 8^{-}}\right)$

Plasma cell myeloma/monoclonal gammopathy of undetermined significance

- Plasma cell infiltrate

- Hypergammaglobulinemia

- Renal failure

- Proteinuria

Vasculitis, particularly eosinophilic granulomatosis with polyangiitis and granulomatosis with polyangiitis
- Eosinophilia in blood and tissue

- Polyclonal hypergammaglobulinemia with elevated serum IgG4

- Peri-aortitis and rarely, Kawasaki-like coronary

arteritis are seen in IgG4-RD

- Multi-organ involvement, including respiratory,
- IgG4-RD rarely involves skin whereas cutaneous lesions (round/oval, red/brown poorly circumscribed macules, papules and plaques) are an obligatory feature of CSP; serum IgG4 in CSP is normal or mildly elevated

- Massive cervical lymphadenopathy is atypical for IgG4-RD

- RDD may present with B symptoms

- Large histiocytic cells with hypochromatic nuclei and pale cytoplasm; emperipolesis; positive for S100, CD68, CD14 and CD163

- $>95 \%$ of ECD patients have bone involvement, which is rare in IgG4-RD (apart from rare IgG4+ angiocentric eosinophilic fibrosis of the head and neck)

- Yellow peri-orbital xanthelasmas common in ECD (skin involvement in IgG4-RD is rare, and when present tends to be erythematous or flesh-colored papules)

- Foamy multi-nucleated histiocytes, few Touton cells, fibrosis; CD68 ${ }^{+}, \mathrm{CD}_{163^{+}}, \mathrm{CD} 1 \mathrm{a}$

- $50 \%$ of ECD patients are BRAF V600E-positive

- B symptoms, bone involvement, brain parenchymal involvement and hypercalcemia are rare in IgG4-RD

- Non-caseating granulomas

- Hypercalcemia and elevated ACE levels

- Increased blasts or myeloid clone in CEL

- PDGFR-alpha/PDGFR-beta/FGFR1/PCM1-JAK2 positivity are not seen in IgG4-RD

- More marked and persistent eosinophilia in HES

- Plasma cell clonality

- Monoclonal paraprotein \pm suppression of polyclonal immunoglobulins

- Lytic boney disease/hypercalcemia

- Light chains in urine rather than albuminuria

- Highly elevated CRP in vasculitis

- Extravascular granulomas, small-medium vessel vasculitis

- Mononeuritis multiplex not a feature of IgG4-RD

\footnotetext{
*Although increased IgG4+ plasma cells have been described in these diseases, the absolute counts and IgG4/IgG ratio are typically well below the thresholds for the diagnosis of IgG4 RD and the other key features of IgG4-RD (storiform fibrosis and obliterative phlebitis) are not seen. ${ }^{3}$ IgG4-LAD: IgG4-lymphadenopathy; IL-6: interleukin-6; CRP: C-reactive protein; IgG4-
} RD: IgG4-related disease; CNS: central nervous system; ACE: angiotensin-converting enzyme; PCR: polymerase chain reaction. 
Erdheim-Chester disease have retroperitoneal fibrosis, which may raise the suspicion of IgG4-RD; however, more than $95 \%$ of patients with Erdheim-Chester disease have skeletal involvement, which, aside from rare cases of IgG4-related angiocentric eosinophilic fibrosis (midline destructive lesions of the head and neck), is generally not seen in IgG4-RD. ${ }^{50}$ The histology of Erdheim-Chester disease shows a $\mathrm{CD}^{+} 8^{+} \mathrm{S} 100^{-} \mathrm{CD} 1 \mathrm{a}^{-}$histiocyte infiltration often with "foamy histiocytes". ${ }^{51}$ Extra-pulmonary sarcoidosis may share clinical features similar to those of IgG4-RD, including polyclonal hypergammaglobulinemia, lymphadenopathy, pulmonary nodules, sclerosing mesenteritis and pachymeningitis. The association between IgG4-RD and malignant lymphoma has been studied extensively. In Asian patients, mucosal-associated lymphoid tissue (MALT) lymphoma, particularly of ophthalmological tissues has been described, whereas in western populations a variety of histologies (diffuse large B-cell, follicular, lymphoplasmacytic, and MALT) have been reported. ${ }^{52,53}$ There are also case reports of IgG4-RD concomitant with autoimmune lymphoproliferative syndrome. ${ }^{54,55}$

\section{Case continued}

The patient was suspected to have IgG4-RD, so serum IgG subclasses were analyzed. His serum IgG4 level was markedly elevated at $11.6 \mathrm{~g} / \mathrm{L}$ (normal values <1.35). The tissue blocks from his previous nephrectomy were retrieved and pathology review showed a lymphoplasmacytic infiltrate, moderate tissue eosinophilia and interstitial fibrosis and atrophy. Staining for IgG4 and IgG revealed abundant IgG4+ plasma cells with $>40$ Ig G $4^{+}$plasma cells per high power field and an IgG4/Ig G ratio $>40 \%$. Computed tomography scans of the neck, chest, abdomen and pelvis revealed multiple pulmonary nodules, carinal lymphadenopathy and a soft tissue density encasing the main coronary arteries, previous right nephrectomy and pancreatic atrophy. His IgG4-RD Responder Index activity score was 12.

\section{Diagnosis and staging}

A careful history and thorough physical examination, attending to clues such as a history of waxing and waning glandular swelling, sicca symptoms and unexplained pancreatitis or jaundice must be accompanied by serum protein studies. Histological confirmation of the disease is essential, and once a diagnosis has been established, investigations to assess for symptomatic and subclinical organ involvement, such as early retroperitoneal fibrosis and albuminuria, are important for management planning. The IgG4-RD Responder Index is a standardized, validated tool for the evaluation of disease activity at initial evaluation and subsequent follow up. ${ }^{56,57}$ Suggested laboratory and imaging tests are summarized in Table 3.

\section{Serum protein studies}

Approximately $70 \%$ of patients with IgG4-RD have an elevated serum IgG4 level. Serum IgG subclasses should be investigated in conjunction with serum protein electrophoresis to exclude a monoclonal paraprotein (Figure 3). Serum IgG4 level has a diagnostic sensitivity ranging from $83-97 \%$ and specificity from $60-85 \%$ with a general cut-off of "above the upper limit of normal". ${ }^{58-60}$ Typically, $1.35 \mathrm{~g} / \mathrm{L}$ is used as the biomarker cut-off for IgG4-RD (which corresponds to the upper limit of normal for one common commercial method but not another) without specifying the methodology. While mildly elevated serum IgG4 can be seen in many conditions, markedly elevated serum IgG4 (>5 g/L) is approximately $90 \%$ specific for IgG4-RD. Aside from methodological differences, serum IgG4 levels in IgG4-RD can vary greatly depending on ethnicity and degree of organ involvement. In the Boston cohort of patients (76\% White), only 53 of 103 patients had elevated serum IgG4 levels. ${ }^{16}$ In contrast, in a cohort of 334 Japanese patients, more than $95 \%$ had elevated serum IgG4. ${ }^{17}$ In our multi-ethnic cohort, we found that Asians have a higher serum IgG4 than non-Asians (median $11.2 \mathrm{~g} / \mathrm{L}$ versus $2.9 \mathrm{~g} / \mathrm{L}, P=0.0094$ ), and elevated serum IgG4 had a sensitivity of $96 \%$ in Asians compared to $67 \%$ in non-Asians. ${ }^{61}$ Patients with multi-organ involvement or of Asian ethnicity typically have elevated serum IgG4, sometimes markedly so, such as the patient in this illustrative case. The serum IgG4/IgG ratio is typically $>0.2$ in patients with IgG4-RD, although the ratio does not increase the diagnostic specificity of serum IgG4 alone. Flow cytometric detection of plasmablasts may offer a more sensitive modality for diagnosing IgG4-RD, with a reported sensitivity of $95 \%$ and specificity of $82 \%$ using a cut-off of $900 / \mathrm{mL}$. ${ }^{62}$ However, the flow cytometry method used to detect plasmablasts is not widely available.

Most centers use immunonephelometry to measure IgG subclasses, which can cause some challenges with interpretation. The two most common immunonephelometric methods (Siemens and Binding Site) correlate well with regard to IgG4, but the absolute IgG4 values differ by approximately $50 \%$ at the upper limit of normal. ${ }^{63}$ IgG4 levels may also be markedly under-reported in cases of extreme IgG4 elevations due to the hook effect. The hook effect, or prozone phenomenon, occurs when an excessive amount of analyte prevents binding of the capture antibody in a sandwich assay, yielding a falsely low or normal result. Erroneously low measurements of serum IgG4 reported in the literature reflect this error. ${ }^{64}$ Furthermore, IgG4 itself interferes with the nephelometric measurement of IgG1 and IgG2, in particular, which can obscure the immunoglobulin profile that would otherwise highlight the disproportionate elevation of serum IgG4. ${ }^{65}$ Because of the traditional errors in immunonephelometry, some have mistakenly reported increased serum IgG2 levels as a marker of IgG4-RD. ${ }^{66-68}$ Our group has recently demonstrated that mass spectrometry is an alternative that eliminates these analytical errors and is more costeffective than immunonephelometry. ${ }^{65}$

\section{Histopathology}

A firm diagnosis of IgG4-related disease requires histopathological confirmation, except in the case of autoimmune pancreatitis, in which radiological features (diffuse "sausage-like" enlargement of the pancreas with featureless borders and delayed enhancement with or without a capsule-like rim or "halo") may be sufficiently specific to exclude requirement for tissue biopsy. ${ }^{3,69}$ As in sarcoidosis, in which non-caseating granulomas may be seen in any of the organs affected by the disease, IgG4-RD demonstrates common histology in most of the multitude of organs that may be affected.

The three major histological features of IgG4-RD in tissue are: (i) a dense, polyclonal lymphoplasmacytic infiltrate enriched with IgG4+ $4^{+}$lasma cells; (ii) fibrosis; and (iii) obliterative phlebitis. With regards to the lymphoplasma- 
Table 3. Diagnostic and staging tests in IgG4-RD.

\begin{tabular}{|c|c|c|}
\hline & Test(s) & Typical findings \\
\hline \multirow{8}{*}{ Blood and urine tests } & Complete blood count/differential/blood film & $\begin{array}{l}\text { Eosinophilia ( } \sim 40 \% \text { of patients, typically mild); } \\
\text { rouleaux formation due to polyclonal } \\
\text { hypergammaglobulinemia }\end{array}$ \\
\hline & $\begin{array}{l}\text { C-reactive protein (CRP); interleukin- } 6 \text { and other } \\
\text { markers of systemic inflammation }\end{array}$ & $\begin{array}{l}\text { Normal or moderately elevated (CRP typically } \\
<20 \mathrm{mg} / \mathrm{L} \text { ) in the absence of peri-aortitis or active } \\
\text { infection }\end{array}$ \\
\hline & Serum IgG subclasses & $\begin{array}{l}\text { Mildly elevated IgG4 }<1.5-5 \mathrm{~g} / \mathrm{L} \text { is nonspecific, and } 30 \% \\
\text { of IgG4-RD patients have normal serum IgG4 levels. } \\
\text { Serum IgG4 }>5 \mathrm{~g} / \mathrm{L} \text { is helpful both for diagnosis and } \\
\text { as a disease marker. Other IgG subclasses may be } \\
\text { moderately elevated (IgG4/IgG ratio is typically }>0.2 \text { )* }\end{array}$ \\
\hline & $\begin{array}{l}\text { Immunoglobulins (IgG, IgA, IgM, IgE); serum and urine } \\
\text { protein electrophoresis (SPEP, UPEP) }\end{array}$ & $\begin{array}{l}\text { IgA and IgM may be normal or mildly increased; IgE } \\
\text { may be markedly increased. Immunoglobulin } \\
\text { suppression is atypical. SPEP and UPEP are important } \\
\text { to rule out monoclonal proteins }\end{array}$ \\
\hline & $\begin{array}{l}\text { Autoantibodies (e.g. antinuclear antibody, } \\
\text { rheumatoid factor) }\end{array}$ & May be weakly positive \\
\hline & Complements (C3/C4) & Often low, especially with tubulointerstitial nephritis \\
\hline & Urinalysis, random albumin/creatinine ratio & $\begin{array}{l}\text { Albuminuria is common; nephrotic range proteinuria } \\
\text { can be seen with membranoproliferative } \\
\text { glomerulonephritis }\end{array}$ \\
\hline & $\begin{array}{l}\text { Other markers of end organ damage: lipase, glucose } \\
\text { and hemoglobin Alc, liver enzymes, thyroid-stimulating } \\
\text { hormone, creatinine, urinalysis, urine } \\
\text { albumin/creatinine ratio }\end{array}$ & $\begin{array}{l}\text { Subclinical pancreatitis with elevated lipase, glucose } \\
\text { intolerance, hepatitis and albuminuria are common }\end{array}$ \\
\hline \multirow[t]{2}{*}{ Imaging } & $\begin{array}{l}\text { Computed tomography (CT) of the neck, chest, } \\
\text { abdomen, pelvis }\end{array}$ & $\begin{array}{l}\text { Diffuse "sausage-like" or segmental enlargement of } \\
\text { pancreas, often with a "halo"; wedge-shaped hypodensities } \\
\text { in kidneys; ductal organs, such as bile duct and bronchus, } \\
\text { show diffuse "pipe-stem" wall thickening; thickened aortic } \\
\text { wall; hepatic mass lesions; retroperitoneal fibrosis or } \\
\text { peri-aortic cuffing }\end{array}$ \\
\hline & $\begin{array}{l}\text { If lacrimal enlargement } \Rightarrow \text { CT to head (rule out } \\
\text { orbital involvement) }\end{array}$ & $\begin{array}{l}\text { Patients with orbital disease typically have lacrimal } \\
\text { gland swelling }\end{array}$ \\
\hline \multirow{4}{*}{ Pathology } & Archived specimens & $\begin{array}{l}\text { As long as tissue blocks are still available, the pathologist } \\
\text { should be able to examine the histology and then order } \\
\text { immunostaining for IgG4 and IgG if typical features are present }\end{array}$ \\
\hline & New biopsy & $\begin{array}{l}\text { Excisional is preferable to core biopsy when possible to look } \\
\text { for the central pathological features: } \\
\text { - Storiform fibrosis } \\
\text { - Obliterative phlebitis } \\
\text { - Polyclonal lymphoplasmacytic infiltrate with increased } \\
\text { IgG4+ plasma cells and } \mathrm{IgG}^{+} / \mathrm{IgG}^{+} \text {plasma cell } \\
\text { ratio }>40 \% * *\end{array}$ \\
\hline & & $\begin{array}{l}\text { Consider minor salivary gland (lip) biopsy if affected organs } \\
\text { are high risk for biopsy }\end{array}$ \\
\hline & Lymph node and bone marrow & $\begin{array}{l}\text { These tissues are unusual in that fibrosis and obliterative } \\
\text { phlebitis are typically not seen, and thus biopsy of other } \\
\text { tissues may be required for a definitive diagnosis. Involved } \\
\text { lymph nodes typically have }>100 \text { IgG4+ plasma cells/hpf } \\
\text { with an IgG4/IgG ratio }>40 \% \text {. Bone marrow involvement with } \\
\text { eosinophilia and increased IgG4+ plasma cells is rare and } \\
\text { may be absent even in patients with marked serum } \\
\text { hypergammaglobulinemia }\end{array}$ \\
\hline
\end{tabular}

${ }^{*}$ IgG2 may be spuriously elevated when nephelometric measurement is used. ${ }^{65 *}$ The number of IgG4 4 cells/hpf required varies, depending on the tissue, from $>10 /$ hpf in meningeal tissue to $>200 / \mathrm{hpf}$ in skin. In all tissues, the ratio of IgG4+ to IgG+ plasma cells should be $\geq 40 \% .{ }^{3} \mathrm{Hpf}$ : high-power field. 
cytic infiltrate, the number of IgG4+ $4^{+}$plasma cells per highpower field (hpf) considered diagnostic varies according to tissue site, from $>10 / \mathrm{hpf}$ in meninges to $>100 / \mathrm{hpf}$ in skin. Regardless of the site, the ratio of $\mathrm{IgG}^{+} / \mathrm{IgG}^{+}$plasma cells is $>40 \%$ in IgG4-RD. Fibrosis is a histological requirement for the diagnosis of IgG4-RD and should be arranged at least focally in a storiform pattern. Storiform fibrosis is a swirling, "cartwheel" pattern of fibrosis which may have a patchy distribution and can, therefore, be missed with small biopsies. In the obliterative phlebitis of IgG4-RD, venous channels are obliterated by an inflammatory lymphoplasmacytic infiltrate. Expert pathologists recommend looking for arteries/arterioles where the accompanying venous vessel is not readily apparent and may in fact have been replaced by an inflammatory infiltrate; elastin stains may be helpful in identifying completely obliterated vessels.

Other histopathological features include phlebitis without obliteration of the lumen and increased number of eosinophils. As in the illustrative case, archival specimens may be used to confirm a diagnosis, and many patients will have previous biopsies available due to their chronic disease course. As long as a tissue block is still available, IgG4 and IgG stains can be done. When a new biopsy is required, excisional specimens are preferred over core needle biopsies to allow for proper assessment. There are currently no established criteria for the cytological diagnosis of IgG4-RD from a fine needle aspirate.

Increased numbers of IgG4+ $4^{+}$plasma cells are seen in all tissues affected by IgG4-RD, but this is not, in itself, a specific finding. Many chronic inflammatory conditions such as vasculitis, inflammatory bowel disease and lymphoma may exhibit increased numbers of IgG4+ $4^{+}$plasma cells but do not share the other histological features of storiform fibrosis, obliterative phlebitis and absence of granulomatous inflammation. ${ }^{19,21}$ Unfortunately, for the purposes of hematologists, bone marrow involvement is uncommon in IgG4-RD and obliterative phlebitis and storiform fibro- sis (not to be confused with myelofibrosis) are not typically seen in bone marrow and lymph nodes. ${ }^{70}$ Furthermore, even when involved, lymph nodes and bone marrow may not show robust elevation in IgG4-expressing plasma cells as compared to the total $\operatorname{IgG}$ population, or the findings may be only focal. Patterns of IgG4-RD have not been well established in the bone marrow, but the presence of mature plasma cells would be supportive of marrow involvement, once plasma cell neoplasms are excluded. Some examples of marrow involvement in IgG4-RD are shown in Figure 4.

In general, only organs with clinical or radiological evidence of involvement are likely to show diagnostic features on biopsy, and thus biopsy should be directed at affected organ(s). Patients with proteinuria or renal lesions on imaging may require kidney biopsy, and renal involvement may demonstrate two distinct histological patterns: hypocomplementic tubulointerstitial nephritis in $80 \%$ of cases, and membranoproliferative glomerulonephritis in $20 \%$ of $_{\text {cases. }}{ }^{70}$ In patients in whom affected organs are not amenable to biopsy, minor salivary gland (lip) biopsy should be considered. Even without clinical evidence of major salivary gland swelling or sicca symptoms, minor salivary gland biopsy can be a minimally invasive way to reach a histological diagnosis in some patients. One study of 66 patients with suspected IgG4-RD reported a sensitivity of $55 \%$ and specificity of $100 \%$ for labial salivary gland biopsy. ${ }^{71}$ From a pragmatic perspective, patients who have classic clinical, laboratory and radiological manifestations of IgG4-RD but are too frail to undergo an attempted biopsy attempt, or in whom small biopsies yield insufficient diagnostic material, ${ }^{72}$ can be given a working diagnosis of "suspected IgG4-RD" and treated as such provided reasonable efforts have been made to exclude mimickers of IgG4-RD.

Splenic involvement in IgG4-RD remains an enigma. Overt splenomegaly and splenic lesions are rare in confirmed cases of IgG4-RD. A rare entity known as scleros-

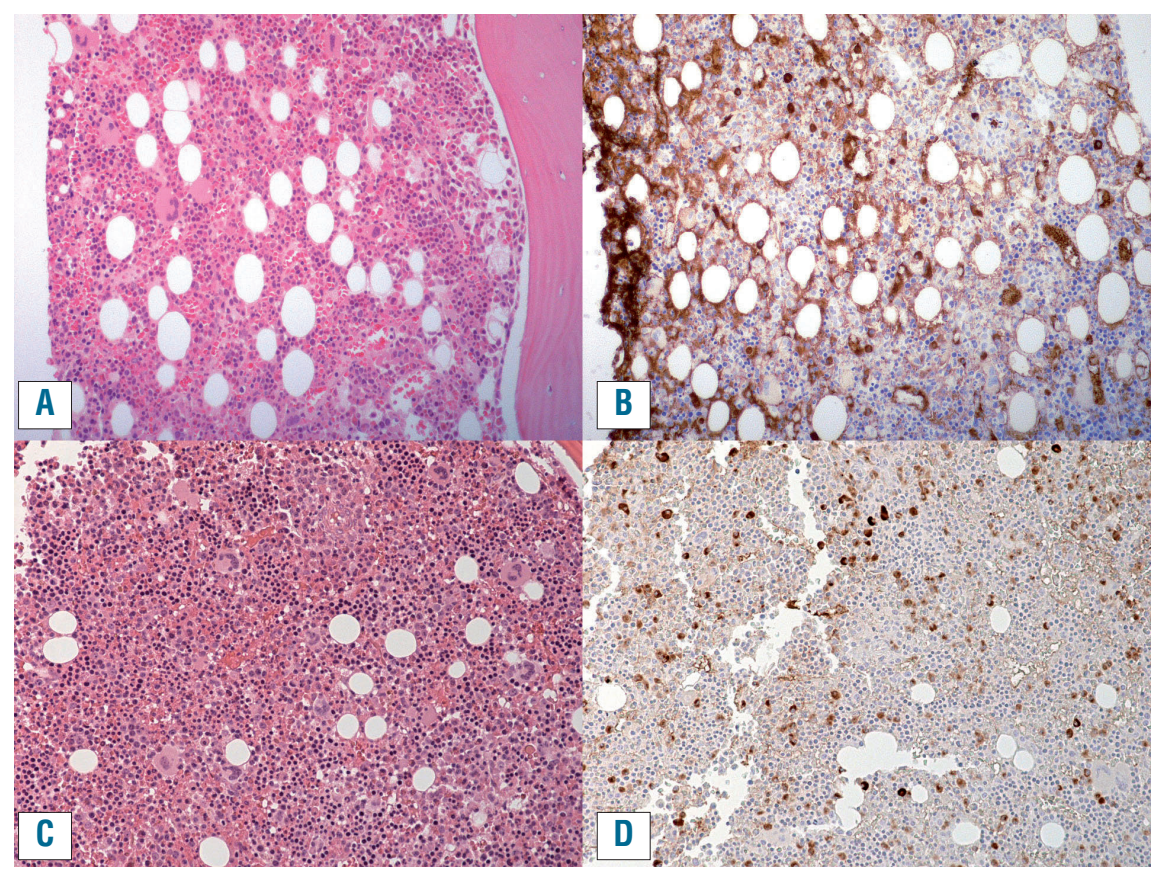

Figure 4. Bone marrow specimens involved by IgG4-related disease. Both cases show mature plasma cells distributed throughout the marrow. Ancillary studies established that these plasma cells were polyclonal, excluding a plasma cell neoplasm. (A,C) Hematoxylin and eosin stains. (B,D) IgG4 immunohistochemistry. 
ing angiomatoid transformation of the spleen (SANT) is known to be enriched with IgG4+ plasma cells, but whether this condition is part of the spectrum of IgG4-RD remains unclear, as many patients with sclerosing angiomatoid transformation of the spleen do not exhibit other features of IgG4-RD. ${ }^{73}$ The inability to biopsy splenic tissue short of full splenectomy hinders the histological characterization of IgG4-RD in this organ.

\section{Imaging and staging}

Once histopathological confirmation of the diagnosis has been obtained, the disease can be staged by computed tomography of the chest, abdomen and pelvis. ${ }^{74}$ Although the orbit is a commonly involved organ in IgG4-RD, the absence of dacryoadenitis is suggestive that there is no underlying orbital pseudotumor and therefore dedicated head or orbital computed tomography is not always necessary. ${ }^{75}$ Positron emission tomography/computed tomography showed greater sensitivity for the detection of disease in arteries, salivary glands and lymph nodes in a study of 21 patients but further evaluation is needed to clarify which patients benefit from the combined tomographic method over conventional imaging. ${ }^{76}$ It is important to check the urinary albumin/creatinine ratio and serum C3/C4 levels to assess for renal involvement. IgG4-RD often behaves indolently, but accurate diagnosis and staging are crucial because some patients have asymptomatic but potentially organ- or life-threatening disease such as retroperitoneal fibrosis, peri-aortitis or coronary arteritis, the last of which may develop suddenly. Moreover, fibrotic disease is typically irreversible, so early treatment is important.

\section{Case continued}

Given the patient's multi-organ involvement, particularly of the coronary arteries, he was treated with two doses of rituximab $1 \mathrm{~g}$ administered intravenously 2 weeks apart. His IgG4 level improved from $11.6 \mathrm{~g} / \mathrm{L}$ to $5.84 \mathrm{~g} / \mathrm{L}$ after 6 months. A repeat computed tomography scan of the chest and abdomen showed improvement of his coronary artery vasculitis, pulmonary nodules and lymphadenopathy and his post-treatment IgG4-RD Responder Index activity score was 3.

\section{Treatment}

Steroids are the first-line therapy for most patients, with an overall response rate of $93 \%$ and complete response rate of $66 \%$ in a phase 2 trial of 44 patients with IgG4-RD from Japan. ${ }^{77}$ The regimen used in this trial was prednisone $0.6 \mathrm{mg} / \mathrm{kg} /$ day initially with a gradual decrease of 5 mg every 2 weeks. ${ }^{77}$ Patients with higher eosinophil count, lacrimal gland involvement, five or more organs involved, and higher IgG4-RD Responder Index scores were at higher risk of glucocorticoid failure in a Chinese cohort of 215 patients. ${ }^{78}$ Some suggest a maintenance dosage of prednisone $5 \mathrm{mg}$ daily for autoimmune pancreatitis specifically, which, as one would expect, decreases relapse rates compared to placebo. ${ }^{79}$ However, the toxicity associated with steroids is well known, with $40 \%$ of patients experiencing new or worsening diabetes. Blood glucose levels should be checked regularly in all patients receiving steroid therapy and many of our patients are also followed by a diabetes specialist. Disease-modifying anti-rheumatic drugs are not very effective for induction of remission but may have a role in maintenance of remis- sion for some patients..$^{80-82}$ In the absence of prospective clinical trials, an international consensus guideline on IgG4-RD treatment had only a $46 \%$ expert agreement on whether disease-modifying anti-rheumatic drugs should be started from the outset of treatment or not. ${ }^{83}$

Rituximab has been shown to be highly effective for IgG4-RD, with a response rate of $97 \%$ (29 out of 30 patients) in one prospective trial. ${ }^{74}$ The majority of patients did not require concomitant corticosteroids from the time of enrollment. However, rituximab is difficult to access due to cost, particularly outside of the USA, and remissions are often short-lived. In a French database study of 33 patients who received rituximab, a clinical response was seen in 29/31 (93.5\%) patients, but 13/31 $(41.9 \%)$ responders relapsed during a mean follow up of 24.8 months (with the relapses occurring at a mean of 19 months after rituximab therapy). ${ }^{84}$ The severe infection rate was estimated to be $12.1 / 100$ patient years and three patients had hypogammaglobulinemia $<5 \mathrm{~g} / \mathrm{L}$. In our practice, we often keep patients on a low dose of maintenance prednisone to maintain remission after rituximab treatment.

A number of emerging therapeutic options show promise. An open label, phase 2 clinical trial of a humanized anti-CD19 antibody (Xmab ${ }^{\circledR 871}$ ) showed that this treatment decreased the IgG-RD Responder Index score by $\geq 2$ points in $12 / 12$ patients who completed the study. ${ }^{85}$ Successful use of lymphoma chemoimmunotherapy regimens such as fludarabine and rituximab and bendamustine and rituximab have been reported for two steroidand rituximab-refractory cases. ${ }^{28}$ Whether these patients needed T-cell directed therapy or simply more potent immunosuppression than can be achieved by steroids or rituximab alone requires further exploration. Elotuzumab is an enticing agent because of the expression of SLAMF7 both on circulating plasmablasts and on the CD4+ cytotoxic T lymphocytes thought to drive the disease process. Anti-IgE therapy with omalizumab is also a potential target for those with severe atopic disease or asthma and elevated IgE levels.

\section{Conclusions}

IgG4-RD is an important condition for hematologists to recognize, both because of its common hematologic manifestations of lymphadenopathy, eosinophilia and polyclonal hypergammaglobulinemia, as well as its overlap with other hematologic inflammatory and neoplastic diseases. When IgG4-RD is suspected, measurement of serum IgG subclasses is a simple, non-invasive screening test; levels $>5 \mathrm{~g} / \mathrm{L}$ (normal $<1.35 \mathrm{~g} / \mathrm{L}$ ) are highly suspicious for IgG4-RD. Regardless of serum IgG4 level, the definitive diagnosis requires histology, preferably in an affected organ other than lymph node or bone marrow, to confirm IgG4-RD and to exclude its many mimics. Early recognition and treatment with steroids, rituximab, or other immunosuppressive therapies, is essential to prevent complications such as fibrosis, peri-aortitis, and renal failure.

\section{Key points}

- IgG4-RD is an important cause of eosinophilia, lymphadenopathy and polyclonal hypergammaglobulinemia. 
Hematologists should include IgG4-RD in the differential diagnosis of these abnormalities.

- Other common manifestations of IgG4-RD include autoimmune pancreatitis, obstructive jaundice, orbital pseudotumor, lacrimal and salivary gland swelling, retroperitoneal fibrosis, and tubulointerstitial nephritis.

- Serum protein electrophoresis and IgG subclass evaluation should be performed in patients with suspected IgG4-RD. Serum IgG4 levels are elevated in approximately $70 \%$ of cases. Mildly increased serum IgG4 (1.5-5 g/L) is a non-specific finding, but a markedly elevated level $(>5$ $\mathrm{g} / \mathrm{L}$ ) is $90 \%$ specific for IgG4-RD.

- A firm diagnosis requires histological confirmation based on the International Consensus Criteria which include a dense lymphoplasmacytic infiltrate, storiform fibrosis and obliterative phlebitis. There must be an increased number of IgG4+ $4^{+}$plasma cells with an IgG4:IgG plasma cell ratio $>40 \%$.

- Early recognition and diagnosis are essential because patients typically respond well to steroids or rituximab in the early stages of the disease, but fibrotic disease and late complications such as chronic pancreatitis are often irreversible.

\section{Acknowledgments}

The authors thank the clinicians and pathologists of the IgG4 West working group in Vancouver for their invaluable collaboration, and Dr. Erica Peterson for providing critical comments on the draft of this manuscript.

\section{References}

1. Hamano H, Kawa S, Horiuchi A, et al. High serum IgG4 concentrations in patients with sclerosing pancreatitis. N Engl J Med. 2001;344(10):732-738.

2. Kamisawa T, Funata N, Hayashi Y, et al. A new clinicopathological entity of IgG4-related autoimmune disease. J Gastroenterol. 2003;38(10):982-984.

3. Deshpande V, Zen Y, Chan JK, et al. Consensus statement on the pathology of IgG4-related disease. Mod Pathol. 2012;25(9):1181-1192.

4. Stone JH, Khosroshahi A, Deshpande V, et al. Recommendations for the nomenclature of IgG4-related disease and its individual organ system manifestations. Arthritis Rheum. 2012;64(10):3061-3067.

5. Mahajan VS, Mattoo H, Deshpande V, Pillai SS, Stone JH. IgG4-related disease. Annu Rev Pathol. 2014:9:315-347.

6. Grados A, Vaysse T, Ebbo M, Carbonnel F, Schleinitz N. IgG4-related disease in monozygotic twins: a case report. Ann Intern Med. 2017;166(2):153-155.

7. Karim F, Loeffen J, Bramer W, et al. IgG4related disease: a systematic review of this unrecognized disease in pediatrics. Pediatr Rheumatol Online J. 2016;14(1):18.

8. Stone JH, Zen Y, Deshpande V. IgG4-related disease. N Engl J Med. 2012;366(6):539-551.

9. Tang SH, Lin MH, Du JS, Liu YC, Hsiao HH, Liu TC. IgG4-related disease with bone marrow involvement mimicking multiple myeloma. Br J Haematol. 2017;177(5):673.

10. Geyer JT, Niesvizky R, Jayabalan DS, et al. IgG4 plasma cell myeloma: new insights into the pathogenesis of IgG4-related disease. Mod Pathol. 2014;27(3):375-381.

11. Mattoo H, Mahajan VS, Maehara T, et al. Clonal expansion of CD4(+) cytotoxic T lymphocytes in patients with IgG4-related disease. J Allergy Clin Immunol. 2016;138(3):825-838.

12. Carruthers MN, Park S, Slack GW, et al. IgG4-related disease and lymphocyte-variant hypereosinophilic syndrome: a comparative case series. Eur J Haematol. 2016;98(4):378-387.

13. Mattoo H, Stone JH, Pillai S. Clonally expanded cytotoxic CD4(+) T cells and the pathogenesis of IgG4-related disease. Autoimmunity. 2017;50(1):19-24.

14. Hubers LM, Vos H, Schuurman AR, et al. Annexin A11 is targeted by IgG4 and IgG1 autoantibodies in IgG4-related disease. Gut. 2018;67(4):728-735.

15. Perugino CA, AlSalem SB, Mattoo $\mathrm{H}$, et al. Identification of galectin- 3 as an autoantigen in patients with IgG4-related disease. Allergy Clin Immunol. 2018 May 29. [Epub ahead of print]

16. Wallace ZS, Deshpande V, Mattoo H, et al. IgG4-related disease: clinical and laboratory features in one hundred twenty-five patients. Arthritis Rheumatol. 2015;67(9): 2466-2475.

17. Yamada K, Yamamoto M, Saeki $T$, et al New clues to the nature of immunoglobulin G4-related disease: a retrospective Japanese multicenter study of baseline clinical features of 334 cases. Arthritis Res Ther. 2017;19(1):262.

18. Sato Y, Kojima M, Takata K, et al. Systemic IgG4-related lymphadenopathy: a clinical and pathologic comparison to multicentric Castleman's disease. Mod Pathol. 2009:22(4):589-599.

19. Cheuk W, Chan JK. Lymphadenopathy of IgG4-related disease: an underdiagnosed and overdiagnosed entity. Semin Diagn Pathol. 2012;29(4):226-234.

20. Wick MR, O'Malley DP. Lymphadenopathy associated with IgG4-related disease: diagnosis \& differential diagnosis. Semin Diagn Pathol. 2017;35(1):61-66.

21. Chang SY, Keogh KA, Lewis JE, et al. IgG4positive plasma cells in granulomatosis with polyangiitis (Wegener's): a clinicopathologic and immunohistochemical study on 43 granulomatosis with polyangiitis and 20 control cases. Hum Pathol. 2013;44(11): 2432-2437.

22. Menon MP, Evbuomwan MO, Rosai J, Jaffe ES, Pittaluga S. A subset of Rosai-Dorfman disease cases show increased IgG4-positive plasma cells: another red herring or a true association with IgG4-related disease? Histopathology. 2014;64(3):455-459.

23. Della Torre E, Mattoo H, Mahajan VS, Carruthers M, Pillai S, Stone JH. Prevalence of atopy, eosinophilia, and IgE elevation in IgG4-related disease. Allergy. 2014;69(2): 269-272.

24. Gotlib J. World Health Organizationdefined eosinophilic disorders: 2017 update on diagnosis, risk stratification, and management. Am J Hematol. 2017;92(11):12431259

25. Chen YY, Khoury P, Ware JM, et al. Marked and persistent eosinophilia in the absence of clinical manifestations. J Allergy Clin Immunol. 2014;133(4):1195-1202.

26. Hu Z, Boddu PC, Loghavi S, et al. A multimodality work-up of patients with hypereosinophilia. Am J Hematol. 2018;93(11): 1337-1346.

27. Chen LY, Lai EJ, Collins DR, Ostrow DN, Sreenivasan GM. A young woman with episodic angioedema, papilledema, and eosinophilia. Am J Hematol. 2010;85(2):124127.

28. Chen LY, Wong PC, Noda S, Collins DR Sreenivasan GM, Coupland R. Polyclonal hyperviscosity syndrome in IgG4-related disease and associated conditions. Clin Case Rep. 2015;3(4):217-226.

29. Khoury P. Lymphocytic-variant hypereosinophilic syndromes. The Hematologist. 2017;14(6):6.

30. Mohammad N, Avinashi V, Chan E, Vallance BA, Portales-Casamar E, Bush JW Pediatric eosinophilic esophagitis is associated with increased lamina propria immunoglobulin G4-positive plasma cells. J Pediatr Gastroenterol Nutr. 2018;67(2):204209.

31. Chen C, Chen K, Huang X, Wang K, Oian S Concurrent eosinophilia and IgG4-related disease in a child: a case report and review of the literature. Exp Ther Med. 2018;15(3): 2739-2748.

32. Clayton F, Fang JC, Gleich GJ, et al Eosinophilic esophagitis in adults is associated with IgG4 and not mediated by IgE. Gastroenterology. 2014;147(3):602-609.

33. Zukerberg L, Mahadevan K, Selig M Deshpande V. Esophageal intrasquamous IgG4 deposits: an adjunctive marker to distinguish eosinophilic esophagitis from reflux esophagitis. Histopathology. 2016;68(7): 968-976.

34. Wong PC, Fung AT, Gerrie AS, et al. IgG4 related disease with hypergammaglobulinemic hyperviscosity and retinopathy. Eur J Haematol. 2013;90(3):250-256.

35. Grados A, Ebbo M, Boucraut J, et al. Serum immunoglobulin free light chain assessment in IgG4-related disease. Int J Rheumatol. 2013;2013:426759.

36. Jawad MD, Go RS, Witzig TE, Mikhael JR, Ravindran A, Murrray DL. Pseudo-monoclonal gammopathy: a report of four cases. Haematologica. 2017;102(11):e466-e469.

37. Jacobs JF, van der Molen RG, Keren DF Relatively restricted migration of polyclonal IgG4 may mimic a monoclonal gammopathy in IgG4-related disease. Am J Clin Pathol. 2014;142(1):76-81

38. Costa MS, Silva A, Costa L, Rodrigues TB, Lemos S, Garrido J. Immunoglobulin G4related disease mimicking multiple myeloma. Port J Nephrol Hypert. 2018;32(3):217 222.

39. Finn WG, Gulbranson R, Fisher S, et al. Detection of polyclonal increases in immunoglobulin G4 subclass by distinct patterns on capillary serum protein electrophoresis: diagnostic pitfalls and clinical 
observations in a study of 303 cases. Am J Clin Pathol. 2016;146(3):303-311.

40. McCudden CR, Jacobs JFM, Keren D, Caillon H, Dejoie T, Andersen K. Recognition and management of common, rare, and novel serum protein electrophoresis and immunofixation interferences. Clin Biochem. 2017;51:72-79.

41. Dispenzieri A, Gertz MA, Therneau TM, Kyle RA. Retrospective cohort study of 148 patients with polyclonal gammopathy. Mayo Clin Proc. 2001;76(5):476-487.

42. Zhao EJ, Carruthers MN, Li CH, Mattman A, Chen LYC. Prevalence of IgG4-Related Disease in Patients with Hypergammaglobulinemia. XXXVII World Congress of the International Society of Hematology (ISH 2018); Sept 14, 2018, 2018; Vancouver, British Columbia, Canada.

43. Engelhart S, Glynn RJ, Schur PH. Disease associations with isolated elevations of each of the four IgG subclasses. Semin Arthritis Rheum. 2017;47(2):276-280.

44. Zheng M, Zhou P, Zheng K, et al. A special subtype of POEMS syndrome: IgG4 subtype. Am J Transl Res. 2016;8(2):588-596.

45. Zhu J, Wu B. Immunoglobulin G4-positive plasma cell myeloma. Blood. 2015;126(19): 2254.

46. Kamisawa T, Zen Y, Pillai S, Stone JH. IgG4related disease. Lancet. 2014;385(9976): 1460-1471.

47. Zhang X, Hyjek E, Vardiman J. A subset of Rosai-Dorfman disease exhibits features of IgG4-related disease. Am J Clin Pathol. 2013;139(5):622-632

48. Emile JF, Abla O, Fraitag S, et al. Revised classification of histiocytoses and neoplasms of the macrophage-dendritic cell lineages. Blood. 2016;127(22):2672-2681

49. Abla O, Jacobsen E, Picarsic J, et al. Consensus recommendations for the diagnosis and clinical management of RosaiDorfman-Destombes disease. Blood. 2018;131(26):2877-2890.

50. Deshpande V, Khosroshahi A, Nielsen GP, Hamilos DL, Stone JH. Eosinophilic angiocentric fibrosis is a form of IgG4-related systemic disease. Am J Surg Pathol. 2011;35(5):701-706.

51. Estrada-Veras II, O'Brien KJ, Boyd LC, et al. The clinical spectrum of Erdheim-Chester disease: an observational cohort study. Blood Adv. 2017;1(6):357-366.

52. Sato Y, Ohshima K, Ichimura K, et al. Ocular adnexal IgG4-related disease has uniform clinicopathology. Pathol Int. 2008;58(8):465470

53. Bledsoe JR, Wallace ZS, Stone JH, Deshpande V, Ferry JA. Lymphomas in IgG4-related disease: clinicopathologic features in a Western population. Virchows Arch. 2017;472(5):839-852.

54. van de Ven A, Seidl M, Drendel V, et al. IgG4-related disease in autoimmune lymphoproliferative syndrome. Clin Immunol. 2017;180:97-99.

55. Langan RC, Gill F, Raiji MT, et al. Autoimmune pancreatitis in the autoimmune lymphoproliferative syndrome (ALPS): a sheep in wolves' clothing? Pancreas. 2013;42(2):363-366

56. Carruthers MN, Stone JH, Deshpande V, Khosroshahi A. Development of an IgG4-
$\mathrm{RD}$ Responder Index. Int $\mathrm{J}$ Rheumatol. 2012;2012:259408

57. Wallace ZS, Khosroshahi A, Carruthers MD et al. An international, multi-specialty validation study of the IgG4-related disease responder index. Arthritis Care Res (Hoboken). 2018;70(11):1671-1678.

58. Carruthers MN, Khosroshahi A, Augustin T, Deshpande V, Stone JH. The diagnostic utility of serum IgG4 concentrations in IgG4 related disease. Ann Rheum Dis. 2015;74(1):14-18

59. Culver EL, Sadler R, Simpson D, et al. Elevated serum IgG4 levels in diagnosis, treatment response, organ involvement, and relapse in a prospective IgG4-related disease UK cohort. Am J Gastroenterol. 2016;111 (5):733-743

60. Masaki Y, Kurose N, Yamamoto M, et al. Cutoff values of serum IgG4 and histopathological IgG4+ plasma cells for diagnosis of patients with IgG4-related disease. Int J Rheumatol. 2012;2012:580814.

61. Oi R, Chen LYC, Park S, et al. Utility of serum IgG4 levels in a multiethnic population. Am J Med Sci. 2018;355(1):61-66.

62. Wallace ZS, Mattoo H, Carruthers M, et al Plasmablasts as a biomarker for IgG4-related disease, independent of serum IgG4 concentrations. Ann Rheum Dis. 2015;74(1):190 195.

63. Parker AR, Carr-Smith HD. Calibration differences and the prozone phenomenon in IgG4-related disease: comment on the article by Khosroshahi et al. Arthritis Rheumatol. 2014;66(7):1964-1965

64. Khosroshahi A, Cheryk LA, Carruthers MN Edwards JA, Bloch DB, Stone JH. Brief Report: spuriously low serum IgG4 concentrations caused by the prozone phenomenon in patients with IgG4-related disease. Arthritis Rheumatol. 2014;66(1):213-217.

65. van der Gugten G, DeMarco ML, Chen LYC, et al. Resolution of spurious immunonephelometric IgG subclass measurement discrepancies by LC-MS/MS. Clin Chem. 2018;64(4):735-742

66. Chan ASY, Mudhar H, Shen SY, et al. Serum IgG2 and tissue IgG2 plasma cell elevation in orbital IgG4-related disease (IgG4-RD): potential use in IgG4-RD assessment. $\mathrm{Br}$ Ophthalmol. 2017;101(11):1576-1582.

67. Dunkley L, Mudhar HS. IgG4-related disease presenting with raised serum IgG2-real timeline of IgG4-RD? Rheumatology. 2017;57(1):197-199

68. Mattman A, Chen LYC, van der Gugten G, et al. Comment on: IgG4-related disease presenting with raised serum IgG2-real timeline of IgG4-RD? Rheumatology. 2018;57(6):1126-1127.

69. Chari ST, Takahashi N, Levy MJ, et al. A diagnostic strategy to distinguish autoimmune pancreatitis from pancreatic cancer. Clin Gastroenterol Hepatol. 2009;7(10) 1097-1103.

70. Mann S, Seidman MA, Barbour SJ, Levin A, Carruthers M, Chen LY. Recognizing IgG4related tubulointerstitial nephritis. Can J Kidney Health Dis. 2016;3:34.

71. Moriyama M, Ohta M, Furukawa S, et al. The diagnostic utility of labial salivary gland biopsy in IgG4-related disease. Mod Rheumatol. 2016;26(5):725-729.
72. Arora K, Rivera M, Ting DT, Deshpande V The histologic diagnosis of IgG4-related disease on small biopsies: challenges and pitfalls. Histopathology. 2018 Nov 8. [Epub ahed of print]

73. Kuo TT, Chen TC, Lee LY. Sclerosing angiomatoid nodular transformation of the spleen (SANT): clinicopathological study of 10 cases with or without abdominal disseminated calcifying fibrous tumors, and the presence of a significant number of IgG4+ plasma cells. Pathol Int. 2009;59(12):844-850.

74. Carruthers MN, Topazian MD, Khosroshah A, et al. Rituximab for IgG4-related disease: a prospective, open-label trial. Ann Rheum Dis. 2015;74(6):1171-1177.

75. Wallace ZS, Khosroshahi A, Jakobiec FA, et al. IgG4-related systemic disease as a cause of "idiopathic" orbital inflammation, including orbital myositis, and trigeminal nerve involvement. Surv Ophthalmol. 2012;57(1): 26-33

76. Ebbo M, Grados A, Guedj E, et al. Usefulness of 2-[18F]-fluoro-2-deoxy-D-glucose-positron emission tomography/computed tomography for staging and evaluation of treatment response in IgG4-related disease: a retrospective multicenter study. Arthritis Care Res (Hoboken). 2014;66(1):86-96.

77. Masaki Y, Matsui S, Saeki T, et al. A multicenter phase II prospective clinical trial of glucocorticoid for patients with untreated IgG4-related disease. Mod Rheumatol. 2017;27(5):849-854.

78. Wang L, Zhang P, Wang M, et al. Failure of remission induction by glucocorticoids alone or in combination with immunosuppressive agents in IgG4-related disease: a prospective study of 215 patients. Arthritis Res Ther. 2018;20(1):65.

79. Masamune A, Nishimori I, Kikuta K, et al Randomised controlled trial of long-term maintenance corticosteroid therapy in patients with autoimmune pancreatitis. Gut 2017;66(3):487-494

80. Hart PA, Topazian MD, Witzig TE, et al Treatment of relapsing autoimmune pancreatitis with immunomodulators and rituximab: the Mayo Clinic experience. Gut 2013;62(11):1607-1615.

81. Yunyun F, Yu C, Panpan Z, et al. Efficacy of cyclophosphamide treatment for immunoglobulin G4-related disease with addition of glucocorticoids. Sci Rep. 2017;7(1):6195

82. Yunyun F, Yu P, Panpan Z, et al. Efficacy and safety of low dose mycophenolate mofetil treatment for immunoglobulin G4-related disease. Rheumatology (Oxford, England). 2018 Aug 14. [Epub ahead of print].

83. Khosroshahi A, Wallace ZS, Crowe JL, et al International consensus guidance statement on the management and treatment of IgG4 related disease. Arthritis Rheumatol 2015;67(7):1688-1699

84. Ebbo M. Grados A, Samson M, et al. Longterm efficacy and safety of rituximab in IgG4-related disease: data from a French nationwide study of thirty-three patients. PLoS One. 2017;12(9):e0183844.

85. Stone JH, Wallace ZS, Perugino CA, et al. A Trial of $\mathrm{XmAb}(\mathrm{R}) 5871$, a reversible inhibitor of CD19+ cells, in IgG4-related disease. Arthritis Rheumatol. 2016;68(Suppl 10). 